\title{
Flora das cangas da Serra dos Carajás, Pará, Brasil: Marattiaceae
}

\author{
Flora of the cangas of Serra dos Carajás, Pará, Brazil: Marattiaceae
}

Alexandre Salino ${ }^{1,2}$ \& Lucas Vieira Lima ${ }^{1}$

\begin{abstract}
Resumo
Este estudo trata os táxons da família Marattiaceae encontrados nas formações ferríferas da Serra dos Carajás, estado do Pará, com descrições, imagens, distribuição e comentários. Na área de estudo foram registrados um gênero e duas espécies: Danaea cartilaginea e Danaea leprieurii. As duas espécies constituem registros novos para o estado do Pará.
\end{abstract}

Palavras-chave: Amazônia, Danaea, flora, novos registros, samambaias eusporangiadas.

\begin{abstract}
This study addresses the Marattiaceae taxa recorded in ferruginous formations of Serra dos Carajás, Pará state, with descriptions, images, geographical distribution, and comments. In the study area one genus and two species were recorded: Danaea cartilaginea and Danaea leprieurii. The two species are new records to Pará state. Key words: Amazonia, Danaea, flora, new records, eusporangiate ferns.
\end{abstract}

\section{Marattiaceae}

Plantas terrícolas ou rupícolas. Caule reptante ou ereto, com escamas ou tricomas. Frondes dimorfas ou monomorfas, com um par de estípulas carnosas na base do pecíolo. Lâmina simples a 4-pinada. Venação livre. Esporângios abaxiais, fundidos, formando um sinângio. Esporos monoletes ou triletes.

Marattiaceae é uma das linhagens mais antigas de samambaias, com representantes que mudaram pouco ao longo de milhões de anos e é conhecida como uma das famílias de samambaias eusporangiadas. Família com distribuição pantropical formada por seis gêneros e aproximadamente 111 espécies (PPG I 2016). No Brasil ocorrem 14 espécies distribuídas em três gêneros (Prado et al. 2015). Na Serra dos Carajás ocorre um gênero com duas espécies.

\section{Danaea Sw.}

Caule curto-reptante ou ereto; frondes 1-pinadas, raramente simples ou 2-pinadas, dimorfas, frondes férteis com tecido laminar reduzido e pecíolo maior ou menor do que nas estéreis, pecíolos e raque com ou sem nós, margem das pinas inteira a erosa, com ou sem gemas. Gênero com cerca de 50 espécies (PPG I 2016), com distribuição estritamente neotropical. Danaea difere dos demais gêneros da família pelas frondes dimorfas, 1-pinadas, raramente simples ou 2-pinadas e sinângios imersos no tecido laminar, geralmente se estendendo da costa até a margem das pinas (Christenhusz 2007). No Brasil ocorrem 12 espécies (Prado et al. 2015), três anteriormente citadas para o Pará (Costa \& Pietrobom 2007; Fernandes et al. 2012) e mais duas aqui referidas para a Serra dos Carajás.

\section{Chave de identificação das espécies de Danaea das cangas da Serra dos Carajás}

1. Caule reptante; pecíolos sem nós; margens das pinas cartilaginosas................ 1.1. Danaea cartaginea

1'. Caule ereto a levemente decumbente; pecíolos com 1-2 nós; margens das pinas não cartilaginosas....

\footnotetext{
${ }^{1}$ Universidade Federal de Minas Gerais, Av. Presidente Antônio Carlos 6627, Pampulha, 31270-901, Belo Horizonte, MG, Brasil.

${ }^{2}$ Autor para correspondência: salinobh@gmail.com
} 
1.1. Danaea cartilaginea Christenh. \& Tuomisto, Kew Bull. 61(1): 18. 2006.

Fig. 1a-b

Plantas terrícolas ou rupícolas. Caule reptante, dorsiventral com até $3 \mathrm{~cm}$ de diâm.; frondes estéreis $134-188 \mathrm{~cm}$ de compr., pecíolos 74-96 cm × 4,5-5,9 mm, sem nós; lâmina 58-62 cm, 1-pinada, concolor, com pina apical conforme nunca substituída por gema, raque não alada; pinas 7-10 pares, 24,5-28 × 4,6-5,2 cm, elíptica-lanceoladas a oblanceoladas, base geralmente cuneada, ápice acuminado a atenuado, margem cartilaginosa, inteira ou com dentículos cartilaginosos na porção apical; nervuras geralmente bifurcadas na base; frondes férteis com até $107-122 \mathrm{~cm}$ de compr., pecíolo com 89-99 cm × 2,7-4,5 mm; lâmina 52-69 cm; pinas 9-12 pares de pinas, $11,2-12 \times 1,8-2,5 \mathrm{~cm}$.
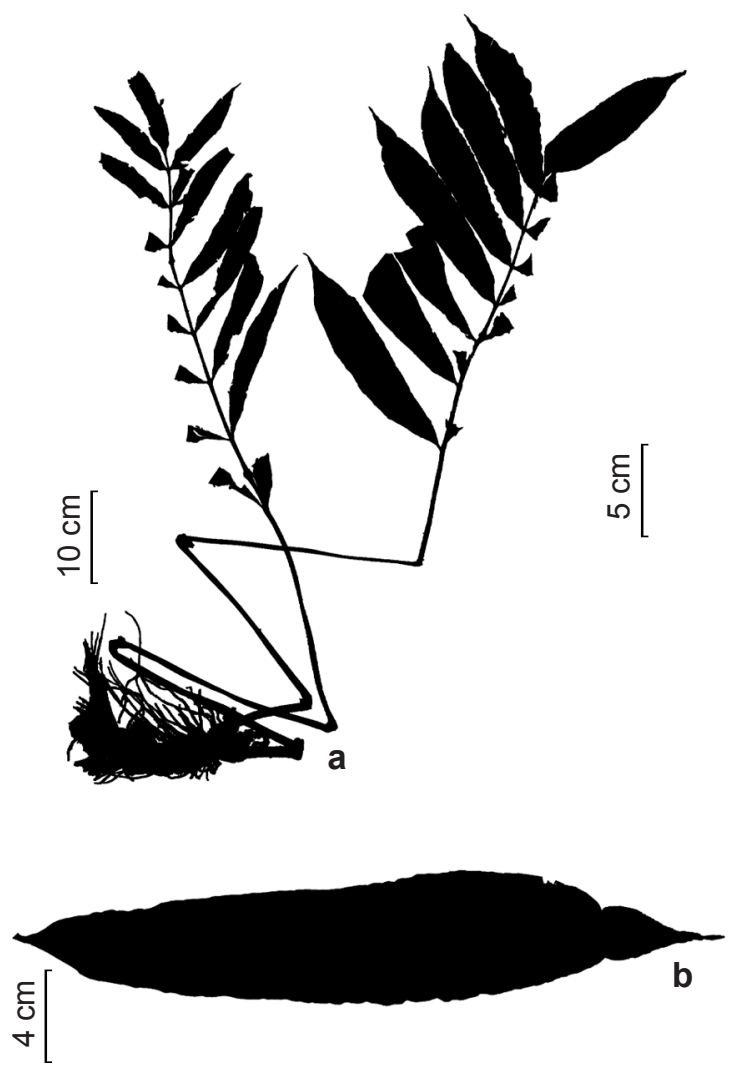

Material selecionado: Canaã dos Carajás, Serra Sul, corpo D, 6²3'15"S, 50²0' $17^{\prime}$ 'W, $690 \mathrm{~m}$, 20.II.2010, T.E. Almeida et al. 2275 (BHCB). Parauapebas, corpo N1, 559'05”'S, 50¹9'03”'W, 268 m, 20.V.2012, A. Salino et al. 15240 (BHCB).

Material adicional examinado: BRASIL. MATO GROSSO: Colider, na rodovia Sinop-Colider, a 22 $\mathrm{km}$ antes de Colider, 14.I.1988, A. Salino (BHCB 29736).

Danaea cartilaginea é uma das maiores espécies do gênero (Christenhusz \& Tuomisto 2006). Esta espécie é frequentemente confundida com D. ulei Christ, mas a última possui o caule ereto e pecíolo com nós, e margem não cartilaginosa, enquanto $D$. cartilaginea possui o caule reptante, pecíolos sem nós e margem cartilaginosa (Christenhusz \& Tuomisto 2006). No Brasil, a espécie era conhecida apenas do estado do Amazonas (Prado et al. 2015), sendo
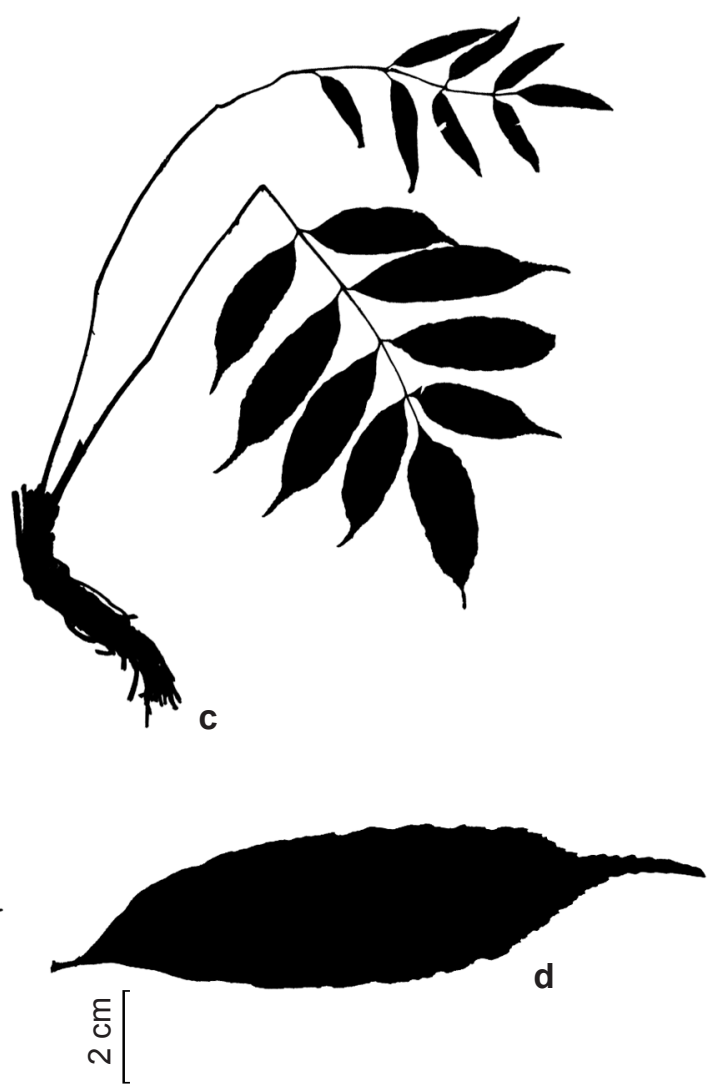

Figura 1 - a-b. Danaea cartilaginea - a. frondes; b. pina mediana. c-d. Danaea leprieurii - c. frondes; d. pina mediana (a-b. T.E. Almeida 2275; c-d. A. Salino 15271).

Figure 1 - a-b. Danaea cartilaginea - a. fronds; b. medial pinna. c-d. Danaea leprieurii - c. fronds; d. medial pinna (a-b. T.E. Almeida 2275; c-d. A. Salino 15271). 
aqui registrada pela primeira vez para os estados do Mato Grosso e Pará.

Ocorre na América do Sul. No Brasil: AM, MT, PA. Serra dos Carajás: Serra Norte: N1, e Serra Sul: S11D. No interior de floresta, próximo a curso d'água, entre 260 e 690 m.

1.2. Danaea leprieurii Kunze, Farnkrauter 1: 137. 1843.

Fig. 1c-d

Plantas terrícolas. Caule ereto a levemente decumbente, cilíndrico com até $1,5 \mathrm{~cm}$ de diâmetro; frondes estéreis $37-72 \mathrm{~cm}$ compr., pecíolo $11-45 \mathrm{~cm}$ compr. $\times 1,8-2,0 \mathrm{~mm}$ de diâmetro, com 1-2 nós; lâmina 23-31 cm, 1-pinada, concolor, com pina apical conforme nunca substituída por gema, raque geralmente não alada; pinas $3-4$ pares, $13,5-15 \times$ 1,5-3,8 cm, oblongas ou oblanceoladas a ovadas, ápice acuminado a caudado, levemente falcado, margem não cartilaginosa, inteira, ocasionalmente levemente crenulada a denticulada na porção apical; nervuras geralmente bifurcadas; frondes férteis 32-45 cm compr, pecíolo 23-30 cm compr. $\times 1,6-1,8 \mathrm{~mm}$ de diâmetro; pinas $1-2$ pares, 3,5-6 $\times 0,7-1,5 \mathrm{~cm}$.

Material selecionado: Canaã dos Carajás, Serra da Bocaina, 6¹8'46”S, 4953'56”W, 687 m, 12.II.2012, L.F.A. Paula et al. 555 (BHCB); Serra Sul, corpo C, 6²1'37'S, 50²2'37'W, 638m, 01.IX.2010, T.E. Almeida et al. 2524 (BHCB). Parauapebas, Serra Norte, N6, 607'22”S, 50¹0'27'W, 674 m, 19.V.2012, A.J. Arruda et al. 1142 (BHCB).

No Brasil, a espécie era conhecida apenas dos estados do Acre, Amazonas e Rondônia (Prado et al. 2015), sendo aqui registrada pela primeira vez para o estado do Pará.

Ocorre na América do Sul. No Brasil: AC, AM, PA, RO. Serra dos Carajás: Serra Norte: N6; e Serra
Sul: S11A, S11C e Serra da Bocaina. Próximo a cursos d'água, interior de floresta, entre 570 e 690m.

\section{Agradecimentos}

Ao CNPq, a bolsa de Produtividade para A. Salino (proc. 306868/2014-8). Ao projeto objeto do convênio MPEG/ITV/FADESP (01205.000250/2014-10) e ao projeto aprovado pelo CNPq (processo 455505/2014-4), o financiamento.

\section{Referências}

Christenhusz MJM (2007) Evolutionary history and taxonomy of Neotropical marattioid ferns: studies of an ancient lineage of plants. Tese de Doutorado. Turun Yliopisto, Turku. 76p.

Christenhusz MJM \& Tuomisto H (2006) Five new species of Danaea (Marattiaceae) from Peru and a new status for D. elliptica. Kew Bulletin 60: 17-30.

Costa JM \& Pietrobom MR (2007) Pteridófitas (Lycophyta e Monilophyta) da Ilha de Mosqueiro, município de Belém, estado do Pará, Brasil. Boletim do Museu Paraense Emílio Goeldi Ciências Naturais 2: 45-55.

Fernandes RS, Maciel S \& Pietrobom MR (2012) Licófitas e monilófitas das Unidades de Conservação da Usina Hidroelétrica - UHE de Tucuruí, Pará, Brasil Hoehnea 39: 247-285.

PPG I - The Pteridophyte Phylogeny Group (2016) A community-derived classification for extant lycophytes and ferns. Journal of Systematics and Evolution 54: 563-603.

Prado J, Sylvestre LS, Labiak PH, Windish PG, Salino A, Barros ICL, Hirai RY, Almeida TE, Santiago ACP, Kieling-Rubio MA, Pereira AFN, Øllgaard B, Ramos CGV, Mickel JT, Dittrich VAO, Mynssen CM, Schwartsburd PB, Condack JPS, Pereira JBS \& Matos FB (2015) Diversity of ferns and lycophytes in Brazil. Rodriguésia 66: 1073-1083.

Lista de exsicatas

Almeida TE 2176 (1.2), 2275 (1.1), 2524 (1.2). Arruda AJ 1142 (1.2). de Paula LFA 555 (1.2). Salino A 15240 (1.1), 15271 (1.2), (1.1). 